Asian J. Med. Biol. Res. 2021, 7 (3), 292-297; doi: 10.3329/ajmbr.v7i3.56139

\author{
Asian Journal of \\ Medical and Biological Research \\ ISSN 2411-4472 (Print) 2412-5571 (Online) \\ www.ebupress.com/journal/ajmbr
}

\title{
Article \\ Seroprevalence and associated risk factors of mycoplasmosis in layer chickens at southern region of Bangladesh
}

Md. Shahjamal Hossain Sobuj ${ }^{1}$, Bidyut Matubber ${ }^{2 *}$, Md. Sahidul Islam ${ }^{3}$, Md. Shamsur Rahman Sumon ${ }^{4}$, Mohammed Lalmoddin Mollah ${ }^{1}$ and Md. Selim Ahmed ${ }^{1 *}$

${ }^{1}$ Department of Medicine, Surgery and Obstetrics, Patuakhali Science and Technology University, Babugonj, Barishal-8210, Bangladesh

${ }^{2}$ Department of Microbiology and Public Health, Khulna Agricultural University, Khulna-9100, Bangladesh

${ }^{3}$ Department of Pathology and Parasitology, Patuakhali Science and Technology University, Babugonj, Barishal-8210, Bangladesh

${ }^{4}$ Department of Physiology and Pharmacology, Patuakhali Science and Technology University, Babugonj, Barishal-8210, Bangladesh

*Corresponding author: Bidyut Matubber (bidyutm78@kau.edu.bd), Department of Microbiology and Public Health, Khulna Agricultural University, Khulna-9100, Bangladesh; Md. Selim Ahmed (selimpstu476@pstu.ac.bd), Department of Medicine, Surgery and Obstetrics, Patuakhali Science and Technology University, Babugonj, Barishal-8210, Bangladesh.

Received: 26 August 2021/Accepted: 28 September 2021/ Published: 30 September 2021

\begin{abstract}
Mycoplasma gallisepticum (MG) is the most important pathogenic Mycoplasma spp. causing avian mycoplasmosis and brought about huge economic losses to poultry industry in Bangladesh. The present study was undertaken to know the seroprevalence of MG in layer birds in three different geographical areas of southern Barishal division, Bangladesh. Total 310 sera samples were collected from wing vein of 30 farms for this study. Sera samples were tested with Rapid Serum Agglutination (RSA) for MG using commercial Antigen Kit (manufactured by Lillidale Diagnostic) to detect the presence of antibodies against MG. The overall seroprevalence of MG by RSA was $36.13 \%$. Seroprevalence of MG infection was dominant in winter season (45.54\%) and significantly highest occurrence was recorded in age groups from 20-40 weeks of layer chickens (51.79\%). Serological investigation in three different upazila of Barishal division showed the highest infection rate $(45.26 \%)$ in medium scale flocks $(1000-3000)$ in comparison to $(21.43 \%)$ small $(<1000)$ flocks. The seroprevalence of MG was highest in Swarupkathi (44.38\%) than in Barishal Sadar (26\%) and Banaripara upazila (28\%). Biosecurity and managemental failure is the overall risk factor in all types of farm due to lack of proper knowledge among farmer. This study reveals the current scenario of mycoplasmosis in layer birds of three different areas of Barishal division.
\end{abstract}

Keywords: Mycoplasma; layer; seroprevalence; risk factor

\section{Introduction}

Poultry industry has made remarkable progress in Bangladesh during the last few decades from a backyard venture to a considerably sophisticated commercial industry (Akhter et al., 2018). It is one of the major developing sectors of livestock in Bangladesh. Poultry contributes about 22-27\% of total animal protein supply in the country (Hamid et al., 2017). It plays a vital role in the rural socio-economic system by contributing significantly on economic growth and simultaneously creating numerous employment opportunities in Bangladesh. There are about 347.035 million poultry populations in Bangladesh (DLS, 2018-19). For human consumption, around $8 \%$ of total animal protein comes from livestock (BBS, 2000). Meat and eggs are two major source of animal protein. Chickens contribute $51 \%$ of total meat production of the country. Per capita annual consumption of meat in the country is $45.621 \mathrm{~kg}$ against the maximum requirement of $43.8 \mathrm{~kg}$ (DLS, 
2018-19). In many regions of Bangladesh, poultry rearing is considered to be the beginning of livestock production (Illango et al., 2003). Poultry production provides a relatively cheaper and quicker means of availing animal protein to the people. The consumption of eggs annually per head in the country is 103.89 against the maximum requirement of 104 eggs (DLS, 2018-19). In spite of the rapid growth of poultry industry, it is still prone to certain threat of infection which may cause great economic losses. Diseases of broiler and layer significantly affect the productivity and health status of chickens (Chanie and Alkie, 2009). Avian mycoplasmosis is a chronic respiratory disease of poultry. The disease causes low mortality, decrease egg production and carcass condemnation of layer birds (Islam et al., 2014). Avian mycoplasmosis is one of the major problems faced by poultry industry all over the world (Piyus et al., 2017). It is caused by four major pathogens viz. 2 Mycoplasma gallisepticum (MG), Mycoplasma synoviae (MS), Mycoplasma meleagrides (MM) and Mycoplasma iowae (MI) (Bradbury, 2001). Mycoplasma gallisepticum (MG) is one of the most important diseases in poultry and infection is particularly important in chickens and turkeys as a cause of respiratory illness and decreased meat and egg production (Bradbury, 2001; Ley, 2013; Basak et al., 2021). In poultry, the infection is spread vertically through infected eggs and horizontally by close contact. The nucleic acid of MG has been identified in environmental samples (Siddique et al., 2012). The clinical signs of MG affected birds are characterized by respiratory signs including conjunctivitis with frothy ocular exudates, sneezing, coughing, nasal discharge, breathing difficulty and closed eyelid (Khan et al., 2018). Unilateral or bilateral sinusitis may also be a feature, particularly in turkeys and game birds which causes swollen infraorbital sinuses and closure of eyelids. Eyelids become swollen with ocular discharge and drainage from the nares can be seen (Muhammad et al., 2017). MS strains exhibit significant variability with respect to their virulence and tissue tropism (Landman and Feberwee, 2004). Postmortem examination reveals mucopurulent exudates in nasal cavities, trachea, and bronchi, fibrinous purulent exudates in pericarditis and perihepatitis (Bradbury et al., 2005; Nascimento et al., 2005). Hossain et al. (2007) reported overall seroprevalence of MG in different flocks as $55.13 \%$ in Rajshahi district, Bangladesh. They found higher prevalence of MG in winter season than summer season. The seroprevalence of MG infection was higher in large flocks in comparison to small flocks. Ali et al. (2015) reported overall prevalence of MG (64.47\%) and (56.13\%), detected by iELISA and SPA test, respectively at some selected areas of Bogura district, Bangladesh. They also found highest prevalence of MG at 50-55 weeks age (69.63\%) as compared with lowest (56-61 weeks). Shoaib et al. (2019) reported the overall seroprevalence of MG is $44.9 \%$ in layer birds where highest prevalence was found in period from October to December. The seroprevalence of MG antibodies was higher in large flocks $(69.63 \%)$ and lower in small flocks (56.82\%). It has been reported that overall seroprevalence of MG in chickens was $15.38 \%$ by Haque et al. (2015) and selected study area was Chittagong, Bangladesh. But, limited investigation of mycoplasmosis has been performed in the selected regions of Barishal, Bangladesh. Considering the above facts, the present work has been undertaken in layer birds with the following objectives:

I) To study the overall seroprevalence of mycoplasmosis in layer chickens at the southern Barishal division, Bangladesh.

II) To determine the associated risk factors of MG infection in layer birds at the mentioned study area.

\section{Materials and Methods}

\subsection{Study area and duration}

The present study was carried out at the different areas of Barishal (Barishal Sadar, Banaripara and Swarupkathi), Bangladesh. The serological diagnosis from collected samples was performed in the Department of Medicine, Surgery \& Obstetrics, Faculty of Animal Science and Veterinary Medicine, Patuakhali Science and Technology University (PSTU), Babugonj, Barishal, and Quality poultry disease diagnostic laboratory, Swarupkathi, Barishal during the period from July 2018 to June 2019.

\subsection{Study Design}

This study was conducted on commercial layer birds of 3 Upazilas (Barishal Sadar, Banaripara and Swarupkathi) of Barishal region in Bangladesh. 30 farms were randomly selected due to the presence of poultry population. A total no. of 310 layer birds were randomly selected from 40,000 birds of 30 different farms from three different Upazilas (Barishal Sadar, Banaripara and Swarupkathi) in Barishal region. The randomly selected birds were divided into three group i.e. 20-40 weeks, $>40$ weeks $(28.57 \%)$ and $<20$ weeks age group. The duration of the study period was also divided into three different seasons Rainy (July-October), Summer (March-June) and Winter (November-February) with a view to observe the seasonal variation. 
2.3. Blood collection and preparation of serum sample for serological test

From each live bird, $2 \mathrm{ml}$ of blood was collected by using sterilized syringes $(5 \mathrm{ml})$ and blood was kept at room temperature for 2 hours. A clean straw-colored serum was seen around the clotted clump. The serum was poured into a labeled screw capped vial and stored at $-20^{\circ} \mathrm{C}$ until use.

\subsection{Rapid serum plate agglutination test (RSPAT)}

Antibodies against the MG in mycoplasmosis suspected poultry sera samples were detected by Rapid Serum Agglutination Test. The test was carried out at room temperature $\left(20-25^{\circ} \mathrm{C}\right)$ within 24 hours of the collection of sera. The RSA test was performed by crystal violet stained MG commercial antigen (MG RSA Antigen) manufactured by Lillidale Diagnostic ${ }^{\circledR}$. For this test, $0.02 \mathrm{ml}$ serum was placed side by side with pipette on a glass plate and add $0.02 \mathrm{ml}$ RSA antigen. After adding, serum and antigen were mixed well by glass rod, followed by rocking. In positive samples, clumps were formed slowly within 2 minutes which could be seen during rocking; whereas, in negative samples, no such granules were observed. Agglutination was assigned score $(+)$ to $(+++)$. The sera sample having agglutination score $(+)$ or greater were recorded as positive and used for calculation of positive and used for calculation of prevalence. However, RSA test may sometimes show false positive reaction. To overcome the false positive reactions then test sera were inactivated by heating at $56^{\circ} \mathrm{C}$ for 30 minutes in a water bath and retested for confirmation of results.

\subsection{Statistical analysis}

The seroprevalence of mycoplasmosis was calculated by considering total number of samples screened for mycoplasmosis and number of samples detected positive as per formula. Seroprevalence of Mycoplasmosis (\%) $=$ Number of positive cases/Total number of screened sample x 100. Data also analyzed by Chi-square test to observe the significant influence of parameters.

\section{Results}

\subsection{Overall prevalence of mycoplasmosis in layer chickens}

Out of 310 birds the overall prevalence of mycoplasmosis in layer chickens at study area was $36.13 \%$ shown in Table 1.

\subsection{Prevalence of mycoplasmosis in layer chickens on the basis of their age}

In present study, prevalence of mycoplasmosis in layer chickens according to the age groups was shown in Table 2. Among the different age groups, significantly highest prevalence was recorded in 20-40 weeks age group $(51.79 \%)$ followed by $>40$ weeks $(28.57 \%)$ and $<20$ weeks age group (19.64\%).

\subsection{Season wise prevalence of mycoplasmosis in layer chickens}

According to seasonal basis of prevalence, highest percentage of mycoplasmosis was recorded in winter season (45.54\%) followed by rainy season (33.04\%) and summer season (21.43\%) shown in Table 3.

\subsection{Seroprevalence of mycoplasmosis in layer chickens in different areas of Barishal}

Seroprevalence of Mycoplasmosis was observed in three different areas of Barishal region. Out of 310 sera samples from three different areas, 50 samples were collected from Barishal Sadar, 100 samples were collected from Banaripara and 160 samples were collected from Swarupkathi. Out of these, 13 (26.00\%) were found positive in Barishal Sadar, 28 (28\%) were found in Banaripara and 71 (44.38\%) were found in Swarupkathi for antibodies shown in Table 4. Highest seroprevalence of Mycoplasmosis caused by MG was observed in Swarupkathi area $71(44.38 \%)$.

\subsection{Seroprepravalence of MG in relation to flock size of layer birds}

Serological study showed that highest infection rate of MG was observed in medium sized flocks (1000-3000) $(45.26 \%)$ followed by small (21.43\%) and large sized flocks (22\%) (Table 5).

Table 1. Overall prevalence of mycoplasmosis in layer chickens.

\begin{tabular}{|l|l|l|}
\hline Total no. of birds & Total no. of infection & Prevalence (\%) \\
\hline 310 & 112 & 36.13 \\
\hline
\end{tabular}


Table 2. Age wise prevalence of Mycoplasmosis in layer chickens.

\begin{tabular}{|l|l|l|l|l|l|}
\hline Breed & No of Infected Birds & Age group (weeks) & Age wise infection & Prevalence (\%) & P value \\
\hline \multirow{3}{*}{ Layer } & \multirow{2}{*}{112} & $<20$ & 22 & 19.64 & $0.004 * *$ \\
\cline { 3 - 5 } & & $20-40$ & 58 & 51.79 & \\
\cline { 2 - 5 } & $>40$ & 32 & 28.57 & \\
\hline
\end{tabular}

$* *=$ Significant at $1 \%$ level of probability

Table 3. Season wise prevalence of mycoplasmosis in layer chickens.

\begin{tabular}{|l|l|l|l|l|l|}
\hline Breed & Total no. of infection & Seasons & Season wise affection & Season wise prevalence (\%) & P value \\
\hline \multirow{3}{*}{ Layer } & \multirow{2}{*}{112} & Rainy & 37 & 33.04 & 0.549 \\
\cline { 3 - 6 } & & Summer & 24 & 21.43 & \\
\cline { 2 - 6 } & & Winter & 51 & 45.54 & \\
\hline
\end{tabular}

Table 4. Area wise seroprevalence of Mycoplasmosis in study area.

\begin{tabular}{|l|l|l|l|}
\hline Area & Total collected samples & MG positive & P Value \\
\hline Barishal Sadar & 50 & $13(26.00 \%)$ & \multirow{2}{*}{1.986} \\
\cline { 1 - 2 } Banaripara & 100 & $28(28.00 \%)$ & \\
\hline Swarupkathi & 160 & $71(44.38 \%)$ & \\
\hline
\end{tabular}

Table 5. Seroprevalence of MG in relation to flock size of layer chickens.

\begin{tabular}{|l|l|l|l|}
\hline Flock size & Total collected samples & MG positive & P value \\
\hline Small $(<1000)$ & 70 & $15(21.43 \%)$ & 2.652 \\
\cline { 1 - 2 } Medium $(1000-3000)$ & 190 & $86(45.26 \%)$ & \\
\hline Large $(>3000)$ & 50 & $11(22.00 \%)$ & \\
\hline Total birds & 310 & 112 & \\
\hline
\end{tabular}

\section{Discussion}

\subsection{Overall prevalence of mycoplasmosis in layer chickens}

A total number of 310 layer chickens were examined from 30 different poultry farms in selected areas of Barishal (Banaripara, swarupkathi, Barishal Sadar) during the period from July 2018 to June 2019. The overall prevalence of mycoplasmosis in layer chickens at study area was $36.13 \%$ shown in Table 1. Haque et al., (2015) reported overall prevalence of mycoplasmosis $15.38 \%$, which is comparatively lower than present study. They also found 73\% SPA positive in broiler and 27\% in layer birds. Hossain et al., (2007) found higher prevalence of MG in different flocks as $55.13 \%$ in Rajshahi district, Bangladesh. The variations between the present and previous findings might be due to difference in the sample size, selection of sample, techniques used in serological diagnosis, geographical locations/topography, climatic condition, management of commercial poultry farm.

\subsection{Prevalence of mycoplasmosis in layer chickens on the basis of their age}

Among the different age groups, significantly highest prevalence was recorded in 20-40 weeks age group (51.79\%) followed by $>40$ weeks $(28.57 \%)$ and <20 weeks age group (19.64\%). (Table 2). Islam et al. (2014) found that prevalence of MG was highest in pullets (60.63\%) followed by adults (55.63\%) and old chickens (51.25\%), which is disinclined to present study. Now-a-days most of the farmers follow proper biosecurity and vaccination in young birds at study area. For this reason, young birds might be less susceptible to MG infection. Ali et al. (2015) reported higher prevalence of MG at 50-55 weeks age (69.63\%) as compared with lowest (5661 weeks) which support the present study. It has also been reported that significantly higher occurrence of mycoplasmosis in young $(72.72 \%)$ compared to adult (44.00\%) (Hossain et al., 2007) which inclined to present findings. The variation in prevalence of mycoplasmosis in different age groups of layer chickens might be assumed that low stocking density and management factor might be responsible for the lower prevalence of MG in aged birds. 
4.3. Season wise prevalence of mycoplasmosis in layer chickens

According to seasonal basis of prevalence, highest percentage of mycoplasmosis was recorded in winter season (45.54\%) followed by rainy season (33.04\%) and summer season (21.43\%) shown in Table 3. Hossain et al. (2007) and Islam et al. (2014) was also found comparatively higher occurrence of MG in winter season 61.48\% and $58.33 \%$ than in summer $47.74 \%$ and $48.89 \%$, respectively which support the present study. Ali et al. (2015) reported highest prevalence of MG infection in December (70.13\%) followed by November (68\%), October (65.67\%), August (63.46\%), September $(58.54 \%)$ and July $(51.78 \%)$ which is more or less similar to present study. The present study reported highest prevalence of MG infection in winter season (75.6\%) followed by summer $(66.3 \%)$ and rainy $(60.8 \%)$ seasons which also in accordance with reports of earlier observation. The contrast between the present and previous findings might be due to sudden change of temperature and cold stress on the birds (Islam et al. 2014).

\subsection{Seroprevalence of mycoplasmosis in layer chickens at different areas of Barishal}

Seroprevalence of Mycoplasmosis was observed in three different areas of Barishal region. Out of 310 sera samples $13(26.00 \%)$ were found positive in Barishal Sadar, 28 (28\%) were found in Banaripara and 71 (44.38\%) were found in Swarupkathi shown in Table 4. Jalil and Islam (2010) reported prevalence of mycoplasmosis in different upazilas of Khulna district, Bangladesh. They also found that increase farm density in certain area is one of the factors associated with higher prevalence of MG infection in chickens which support the present study. It is well known that Swarupkathi upazila of Barishal region is the renowned poultry raising area of Bangladesh. For this reason, increase farm density of that area might be one of the important factors for higher prevalence of the infection as compared with other regions. The variation in the prevalence also might be due to geographical locations, sample size and management of commercial poultry farm.

\subsection{Seroprevalence of MG infection in relation to flock size of layer birds}

Seroprevalence study showed that highest infection rate of MG infection was observed in medium sized flocks (1000-3000) (45.26\%) followed by small (21.43\%) and large sized flocks (22\%) (Table 5). Ali et al. (2015) reported higher prevalence of MG antibodies was observed in large sized flocks (69.63\%) as compared with small flocks (56.82\%) which are not in support of present study. Jalil and Islam (2010) also reported highest prevalence of mycoplasmosis in large scale flocks of the commercial layer farm. Increased prevalence of mycoplasmosis in large scale flocks might be due to the faultiness of management and biosecurity measures (Chandiramani et al., 1996). But in our observation, increased prevalence of mycoplasmosis in medium scale flocks due to high density and improper management practically followed by farmers.

\section{Conclusions}

Mycoplasmosis is still among the most endemic and fatal poultry diseases that constraint chicken production in the study area. The present study revealed overall seroprevalence of MG in layer birds at some selected regions of Barishal was $36.13 \%$. The highest percentage of MG seroprevalance was noted in Swarupkathi Upazila followed by Bairshal Sadar and Banaripara Upazila of Barishal region. According to age wise prevalence, 20-40 weeks age group of layer birds showed highest percentages of MG infection. Seroprevalence study showed that highest infection rate of MG infection was observed in medium sized flocks followed by small and large sized flocks. Also, the higher positive percentage of mycoplasmosis was observed in winter season as compared with other seasons. The MG infection positive birds should be isolated and strict biosecurity measures should be taken in order to take an effective control measure against them. Some other efforts need to make towards educating poultry farmers regarding vaccination program, adoption of appropriate prophylactic or therapeutic measures for adequate control of MG infection in layer bird.

\section{Acknowledgements}

We would like to thank Quality poultry disease diagnostic laboratory, Swarupkathi, Barishal.

\section{Conflicts of Interest}

None to declare.

\section{References}

Akhter AHMT, SS Islam, MA Sufian, M Hossain, SMM Rahman, SML Kabir, MG Uddin, SM Hossin and MM Hossain, 2018. Implementation of code of practices (CoP) in selected poultry farms of Bangladesh. Asian Australas. J. Food Saf. Secur., 2: 45-55. 
Ali MZ, MM Rahman and S Sultana, 2015. Seroprevalence of Mycoplasma gallisepticum antibody by ELISA and serum plate agglutination test of laying chicken. Vet. World, 8: 9-14.

Basak P, B Banowary, S Arju and MZ Hossain, 2021. Isolation and molecular detection of avian mycoplasmosis in selected areas of Mymensingh district in Bangladesh. Asian J. Med. Biol. Res., 7: 182-190.

BBS, 2000. Statistical Pocket Book of Bangladesh. Bangladesh Bureau of Statistics. Ministry of Planning, Govt. of People's Republic of Bangladesh.

Bradbury JM, 2001. Avian Mycoplasmosis, In: Frank Jordan et al. (eds.) Poultry Diseases 5th edn W B 178193.

Bradbury JM, OMSA Wahab, CA Yavari, JP Dupiellet and JM Bove, 2005. Mycoplasma imitans sp. nov. is related to Mycoplasma gallisepticum and found in birds. Int. J. Syst. Evol., 43: 721-728.

Chandiramani NK, V Roeked and OM Olesiuk, 1966. Viability studies with Mycoplasma gallisepticum under different environment conditions. Poult. Sci. J., 45: 1029-1044.

Chanie M and TN Alkie, 2009. Occurrence of concurrent infectious diseases in broiler chickens is a threat to commercial poultry farms in Central Ethiopia. Trop Anim Health Prod., 41: 1309-17.

DLS, 2018-2019. Livestock Economics Sections, 2018-2019.

Hamid MA, MA Rahman, S Ahmed and KM Hossain, 2017. Status of poultry industry in Bangladesh and the role of private sector for its development. Asian J. Poult. Sci., 11: 1- 13.

Haque E, G Uddin and S Akter, 2015. Prevalence of mycoplasmosis of chickens at Kotwali Thana in Chittagong, Bangladesh. J. Fish. Lives., 3: 151.

Hossain KMM, MY Ali and MI Haque, 2007. Sero-prevalence of Mycoplasma gallisepticum infection in chicken in the greater Rajshahi district of Bangladesh. Bangladesh J. Vet. Med., 5: 09-14.

Illango J, A Etoori, M Olupot and J Mabonga, 2003. Rural poultry production in two Agroecological zones of Uganda. Livestock Health Research Institute (LIRI) 10: 531.

Islam M, J Hassan and MSR Khan, 2014. Sero-prevalence of Mycoplasma gallisepticum infection in backyard and commercial layer chickens in Bhola district, Bangladesh. J. Adv. Vet. Anim. Res., 1: 11-15.

Jalil MA and MT Islam, 2010. A Cross-sectional Study for Mycoplasma gallisepticum antibodies in nonvaccinated commercial layer birds in Khulna district. Bangladesh J. Vet. Med., 8: 93-96.

Khan MI, J Ferdous1, MRA Ferdous, MS Islam, K Rafiq and UK Rima, 2018. Study on indiscriminate use of antibiotics in poultry feed and residues in broilers of Mymensingh city in Bangladesh. Progress. Agric., 29: 345-352.

Landman WJ and A Feberwee, 2004. Aerosol induced Mycoplasma synovae arthritis: The synergistic effect of infectious bronchitis infection. Avian Pathol., 33: 591-598.

Ley DH, 2013. Mycoplasma gallisepticum infection. In: Diseases of Poultry. 11th ed.

Muhammad F, SK Fareed, U Zafar, TA Khan and A Ahmad, 2017. Development and evaluation of cultureenhanced Tetra PCR for differential diagnosis of Mycoplasma gallisepticum and M. synoviae. Pak. J. Zool., 49: 2133-2140.

Nascimento ER, VLA Pereira, MGF Nascimento and Barretto, 2005. Avian mycoplasmosis update. Braz. J. Poult. Sci., 7: 1-9.

Piyus TY, NK Singh, Mahajan, N Jindal and M Singh, 2017. Molecular detection of avian mycoplasmas in poultry affected with respiratory infections in Haryana (India). Int. J. Curr. Microbiol. Appl. Sci., 6: 2155-62.

Siddique BA, SU Rahman, I Hussain and G Muhammad, 2012. Frequency distribution of opportunistic avian pathogens in respiratory distress cases of poultry. Pak. Vet. J., 32: 386-89. 